\title{
Chronic anosmia induces depressive behavior and reduced anxiety via dysregulation of glucocorticoid receptor and corticotropin-releasing hormone in a mouse model*
}

\author{
Sangzin Ahn', Hyun-Woo Shin', Usman Mahmood², Roza Khalmuratova', \\ Sea-Yuong Jeon ${ }^{3}$, Hong Ryul Jin ${ }^{4}$, Jung-Seok Choi ${ }^{5}$, Hye-Sun Kim', \\ Dae Woo Kim ${ }^{4}$ \\ Rhinology 54: 80-87, 2016 \\ DOl:10.4193/Rhino15.209 \\ *Received for publication: \\ July 23, 2015 \\ ' Department of Pharmacology and Biological Sciences, Seoul National University College of Medicine, Republic of Korea \\ Accepted: August 27, 2015 \\ 2 Seoul National University College of Natural Sciences, Republic of Korea \\ blic \\ ${ }^{3}$ Department of Otorhinolaryngology-Head and Neck Surgery, Gyeongsang National University College of Medicine, Jinju, Republic \\ of Korea \\ ${ }^{4}$ Department of Otorhinolaryngology-Head and Neck Surgery, Boramae Medical Center, Seoul National University College of Medi- \\ cine, Seoul, Republic of Korea \\ ${ }^{5}$ Department of Psychiatry, Boramae Medical Center, Seoul National University College of Medicine, Seoul, Republic of Korea
}

\begin{abstract}
Background: Olfactory loss is highly prevalent, and comorbid mood disorders are common. Considering olfactory input is highly interconnected with the limbic system, and that the limbic system manages mood, it is predictable that impairments in the sense of smell may result in mood changes.
\end{abstract}

Methodology: Chronic olfactory deficits were induced by repeated intranasal irrigation of $\mathrm{ZnSO}_{4}$ for 12 weeks in $\mathrm{BALB} / \mathrm{c}$ mice. H\&E staining, OMP staining, and potato chip finding test were performed to confirm olfactory loss. Tail suspension, forced swim, and splash tests were performed to evaluate depression, as well as open field, elevated plus maze tests were applied to assess anxiety. The mRNA levels of glucocorticoid receptor (GR) and corticotropin releasing hormone (CRH) were measured by real-time PCR to confirm relevant molecular changes.

Results: Disruption of the olfactory epithelium and olfactory loss was confirmed in histological studies and potato chip finding test. Behavioral tests show that the chronic anosmic state caused increased depression and reduced anxiety. PCR data showed that mRNA levels of GR in the hypothalamus and CRH in the amygdala were significantly decreased.

Conclusions: These results propose that $\mathrm{ZnSO}_{4}$-induced chronic anosmia can cause a depressive and anxiolytic state via decreased hypothalamic GR and amygdalar $\mathrm{CRH}$.

Key words: anosmia, depression, anxiety, glucocorticoid receptor, corticotropin-releasing hormone

\section{Introduction}

Olfactory dysfunction is highly prevalent in the general population, and it may be caused by upper respiratory tract infections, head trauma, neurodegenerative disorders, exposure to toxins, and various inflammatory conditions of the nasal cavity such as allergic rhinitis and chronic sinusitis ${ }^{(1,2)}$. Toxin exposure or inflammation of the olfactory mucosa results in damage of the olfactory neuroepithelium, consequently leading to olfactory dysfunction ${ }^{(3,4)}$. Olfactory loss can result in neuropsychiatric phenotypes, such as emotional changes ${ }^{(5-7)}$. Patients with olfactory dysfunction caused by nasal inflammation have been reported to show higher scores in indices of anxiety and depression compared with control subjects. Recovery of olfaction after treatment correlates with improvement of quality of life 
including depression and anxiety scores ${ }^{(8)}$.

Olfaction is phylogenetically considered to be the most primitive sense, and is known to be interconnected to the primitive areas of the brain, the limbic system. Stimulation of the olfactory system is known to activate the amygdala, hippocampus and orbitofrontal cortex ${ }^{(9)}$. Considering the limbic area is linked with emotion, it is rather predictable that damage of the olfactory system can cause emotional symptoms in humans and animal models. An extreme animal model of olfactory damage is the olfactory bulbectomy $(\mathrm{OB})$, where the olfactory bulb is surgically removed. The OB model shows symptoms of anxiety and depression ${ }^{(10)}$, and has high value in depression research since the symptoms can be reversed by chronic antidepressant treatment (11).

Although previous studies linking olfactory deficits to alteration in emotional state are present, studies that focus on the molecular mechanism are sparse. Moreover, literature focusing on the mechanism of how peripheral deficits of the nasal olfactory neuroepithelium can affect the central nervous system is rare.

In this study, we used an animal model of chronic anosmia induced by repeated intranasal irrigation of $\mathrm{ZnSO}_{4}$ to study the effects of nasal olfactory deficits on emotional behaviors. The chronic anosmic mice were also compared with an established model of anosmia and depression, the OB model. The behavioral alteration in aspect of depression and anxiety was explored alongside with the corresponding changes of molecules in the hypothalamus and amygdala.

\section{Materials and methods}

\section{Animals}

Six-week-old male BALB/c (Samtako Bio Korea, South Korea) mice were randomly divided into three groups and were housed in groups of 3 to 5 in each cage. A 12 h light -12 h dark cycle was applied and the mice had free access to water and food. The chronic anosmia group (CA group, $\mathrm{n}=8$ ) and control group (CONT group, $n=8$ ) received an intranasal instillation with $20 \mu \mathrm{L}$ of $170 \mathrm{mM} \mathrm{ZnSO}_{4}$ or normal saline solution in each nostril (total $40 \mu \mathrm{L}) 3$ times a week for 12 weeks. The olfactory bulbectomy group (OB group, $\mathrm{n}=10$ ) underwent surgery on the first day of the nasal instillation schedule as previously described with minor modifications ${ }^{(12)}$. Briefly, mice were anesthetized and placed on a stereotaxic apparatus. After exposing the skull with a sagittal incision, the olfactory bulbs were exposed by drilling a burr hole over each olfactory bulb. The olfactory bulbs were thoroughly removed by aspiration with a $16 \mathrm{G}$ blunt needle. No further measurements were taken on the OB group to the end of the schedule. After 12 weeks of treatment, the mice were subjected to series of behavioral studies, and sacrificed to collect tissue. All animal experiments were performed following the National Institutes of Health Guidelines for the Humane Treatment of Animals, with approval from the Institutional Animal Care and Committee of Seoul National University (IACUC number SNU130318-3-2).

\section{Potato chip finding test}

To test the olfactory function, potato chip-finding test was performed as previously described with minor modifications 6 weeks after initiation of treatment ${ }^{(8)}$. Briefly, after depriving of food for $24 \mathrm{~h}$, the mice were individually placed in clear plastic test cages $(20 \times 40 \times 15 \mathrm{~cm})$ with fresh bedding of a depth of 5 $\mathrm{cm}$. A piece of a potato chip $(1 \times 2 \mathrm{~cm}$, Pringles Original Potato Chip, Kellogg, MI, USA) was hidden on the bottom of the cage, and its location was alternated around the center of each quadrant for each test. The average latency of two trials for each mouse to find the potato chip was recorded.

\section{Tail suspension test}

Mice were suspended $30 \mathrm{~cm}$ above the floor by adhesive tape placed on approximately $1 \mathrm{~cm}$ from the tip of the tail. The test was recorded for a 10-minute period by a digital camera and analyzed by Ethovision 8.5 software (Noldus, Netherlands). The total duration of immobility, defined as no movement of all four limbs and the head, and latency to the first immobile period were used as parameters. One mouse which managed to selfclimb was excluded from analysis.

\section{Forced swim test}

On the pre-test day, the mice were exposed to water by being placed in a transparent plastic cylinder $(25 \mathrm{~cm}$ high and $15 \mathrm{~cm}$ in diameter) filled with water up to $20 \mathrm{~cm}$ for 5 minutes. After the pre-test, subjects were dried with paper towels under an infrared heater for 5 minutes to prevent hypothermia then returned back to their home cages. Twenty-four hours after the initial exposure, the mice were tested for 10 minutes under identical conditions. The test was videotaped by a digital camera then was analyzed using Ethovision 8.5 software (Noldus). Total time of immobility, which is defined as no movement of all four limbs, and latency to the first immobile period were recorded.

\section{Splash test}

The mice were individually placed in clear plastic test cages (12 $x 28 \times 15 \mathrm{~cm}$ ) with fresh bedding and were habituated for 10 minutes with the lids closed. After the habituation period, a $10 \%$ sucrose solution was squirted twice on the dorsal coat of each mouse with a sprayer, and the mice were moved back into the test cage. A 5 minute trial was recorded by a digital camera, and was analyzed by Ethovision 8.5 software (Noldus). The viscosity of the sucrose solution soils the fur and triggers grooming behavior. Total grooming time after applying the sucrose solution was used as an index of self-care and motivated behavior. 


\section{Open field test}

Spontaneous activity was measured by the open field test. Mice were individually placed in a $40 \times 40 \times 40 \mathrm{~cm}$ clear plastic box. After a 10-minute habituation period, activity was monitored by Opto-Varimex-4 Auto-Track (Columbus Instruments, $\mathrm{OH}, \mathrm{USA}$ ) for 30 minutes. Time spent in corners was calculated as a parameter of anxiety by the instrument's bundled software.

\section{Elevated plus maze}

The elevated plus-maze consisted of two open arms, two closed arms, and a center area, elevated to a height of $50 \mathrm{~cm}$ above the floor (arms are $8 \mathrm{~cm}$ wide, $25 \mathrm{~cm}$ long). After fasting overnight, mice were placed in the center of the maze and were allowed to explore the maze for 10 minutes. The test was recorded by a digital camera attached to the ceiling, and was analyzed by Ethovision 8.5 program (Noldus). Total time spent in open arms was used to assess anxiety of the subjects.

\section{Tissue preparation}

Animals were anesthetized and immediately cardiac-perfused with heparinized PBS. After the brains were removed from the skull, the amygdala and hypothalamus were quickly dissected on an ice-cold plate. The brain tissue was stored in $-70^{\circ} \mathrm{C}$ until RNA extraction. For nasal histologic evaluation, the nasal tissue specimens were fixed in $2 \%$ paraformaldehyde and decalcified in $5 \%$ nitric acid for $4-5$ days at $4^{\circ} \mathrm{C}$. The specimens were excised from the second palatal ridge to the first upper molar teeth. The tissue was dehydrated and processed according to standard paraffin-embedding procedures. The tissue was cut in coronal sections with a thickness of $4 \mu \mathrm{m}$.

\section{Histological studies}

Hematoxylin and eosin (H\&E) staining was conducted for general findings. Immunohistochemical staining was performed by using the polink-2 plus polymerized horseradish peroxidase (HRP) broad DAB Detection System (Golden Bridge International Labs, WA, USA). Briefly, after deparaffinization, the sections were incubated in $3 \%$ hydrogen peroxide for endogenous peroxidase inhibition and microwave-treated in $10 \mathrm{mmol} / \mathrm{L}$ citrate buffer ( $\mathrm{pH}$ 6.0) for heat-induced epitope retrieval. The sections were incubated for $60 \mathrm{~min}$ at room temperature with rabbit anti-mouse olfactory marker protein (OMP) antibody (1:500; Abcam, Cambridge, UK). The sections were incubated in broad antibody enhancer and polymer-HRP and then stained with the DAB Detection System. Finally, slides were counterstained with hematoxylin. Ten areas from nasal mucosal section were chosen randomly for evaluation under high-power fields (x400) and measured by two examiners blinded to the groups.

\section{Real-time PCR}

RNA samples were prepared using the NucleoSpin RNA kit
(Machery-Nagel, Germany) according to the manufacture's protocols. First strand cDNA was synthesized from the RNA samples using AccuPower RocketScript RT Premix (Bioneer, Republic of Korea) and quantitative real-time PCR assays were carried out by using EvaGreen 2X qPCR MasterMix (Applied Biological Materials, Canada) with BioRad CFX96 Real-time PCR Detection System (Bio-Rad Laboratories, CA, USA) and its bundled software. The primer sequences were as follows: GR forward, 5'- TGA TGG GGA ATG ACT TGG GC-3', GR reverse, 5'-CTT CTC TGT CGG GGT AGC AC-3', CRH forward, 5'- ACC TTC TGC GGG AAG TCT TG- 3', CRH reverse, 5'- CGG AGC TGC GAT ATG GTA CA-3', beta-actin forward, 5'-GGC TGT ATT CCC CTC CAT CG-3', beta-actin reverse, 5'-CCA GTT GGT AAC AAT GCC ATG T-3'.

\section{Statistical analysis}

The data are expressed as means \pm standard errors of the mean (SEM) values. SPSS version 21 (IBM, NY, USA) was used for statistical analysis. One-way ANOVA and LSD post hoc test was used to compare among groups. The results were considered statistically significant if $p<0.05$.

\section{Results}

Olfactory epithelium destruction and olfactory functional impairment was observed in CA mice

To confirm ablation of the olfactory epithelium by $\mathrm{ZnSO}_{4}$ instillation, $\mathrm{H} \& \mathrm{E}$ staining and OMP staining were performed. CA mice showed severe disruption of the olfactory epithelium while CONT and OB mice showed intact structure (Figure 1A). OMP-positive cells were significantly decreased in both $C A$ and OB mice (CONT: $7.19 \pm 3.21, n=5 ; C A: 3.44 \pm 1.72, n=4 ;$ OB: 5.39 $\pm 2.41, n=5)$, indicating decreased activity of olfactory sensory receptor neurons (Figure 1B) ${ }^{(13)}$. The functional impairment of olfaction was assessed by potato chip-finding test, which resulted in an increased latency in CA and OB mice (CONT: $116.70 \pm$ $31.24 \mathrm{sec}, \mathrm{n}=5 ; \mathrm{CA}: 276.00 \pm 56.26 \mathrm{sec}, \mathrm{n}=5 ; O B: 321.70 \pm 72.78$ $\mathrm{sec}, \mathrm{n}=5$ ) (Figure $1 \mathrm{C})$.

Depressive behavior was observed in CA mice when assessed with tail suspension, forced swim, and splash tests In order to evaluate depression in mice, a battery of behavioral tests were applied. Tail suspension and forced swim tests are similar tasks to evaluate the behavioral despair of subjects in an inescapable situation ${ }^{(14)}$. In CA and OB mice, increased immobile time in tail suspension and forced swim was documented (tail suspension: CONT: $41.57 \pm 16.50 \mathrm{sec}, \mathrm{n}=5$; CA: $117.54 \pm 28.70$ sec, $\mathrm{n}=5$; OB: $258.25 \pm 41.17 \mathrm{sec}, \mathrm{n}=5$; forced swim: CONT: 103.76 $\pm 28.40 \mathrm{sec}, \mathrm{n}=5$; CA: $228.39 \pm 51.44 \mathrm{sec}, \mathrm{n}=5$; OB: $316.93 \pm 46.32$ sec, $n=5$ ) (Figure $1 A, C)$. Shorter latency to immobility in tail suspension was observed in CA and OB mice (CONT: $215.11 \pm 55.20$ $\mathrm{sec}, \mathrm{n}=5 ; \mathrm{CA}: 72.47 \pm 21.83 \mathrm{sec}, \mathrm{n}=5 ;$ OB: $25.38 \pm 4.66 \mathrm{sec}, \mathrm{n}=5)$ (Figure $2 \mathrm{~B}$ ). Forced swim test results also showed a tendency of 
A
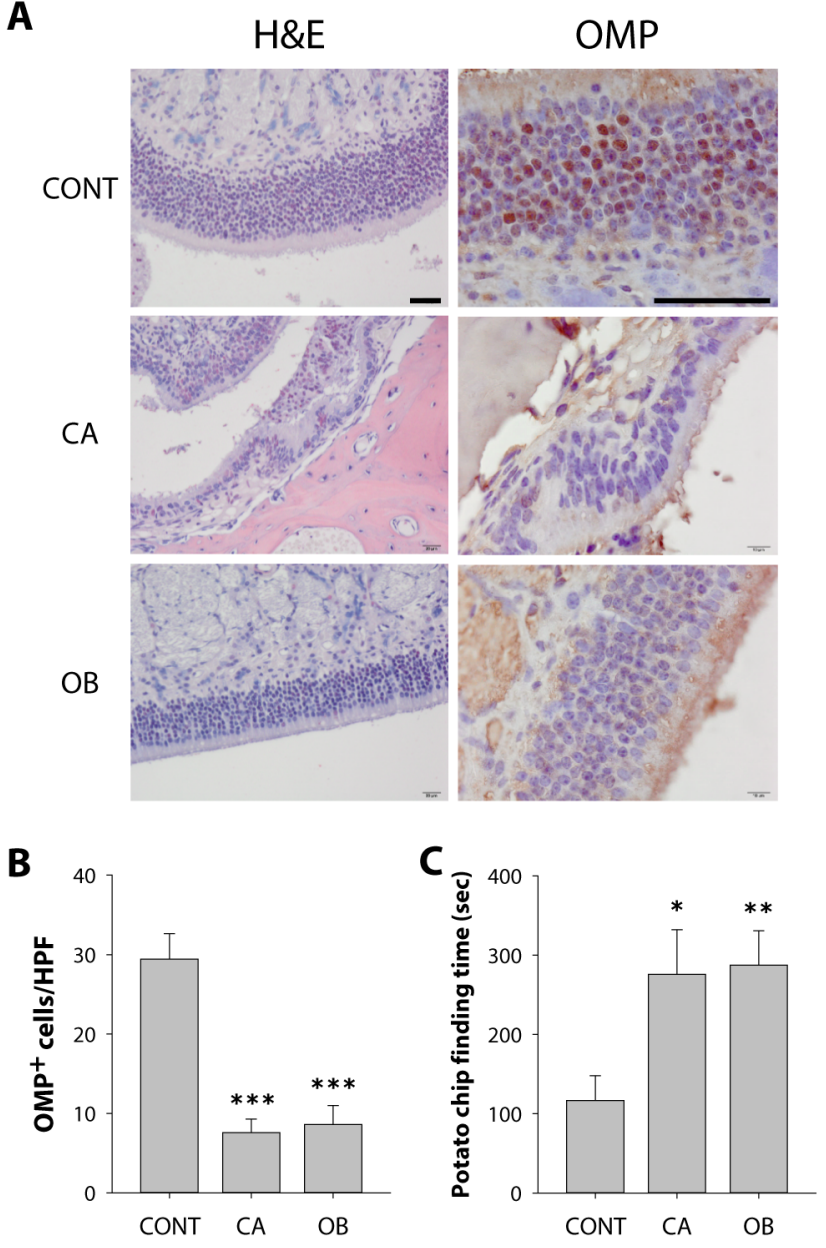

Figure 1. Olfactory epithelium destruction and olfactory functional impairment was observed in CA and OB mice. Nasal tissues were stained with hematoxylin and eosin ( $\mathrm{H} \& \mathrm{E})$ to check disruption of the olfactory epithelium. Immunohistochemistry of olfactory marker protein (OMP) was performed and OMP-positive cells were counted under highpower fields (x400). Olfactory function was measured by potato chip finding test. A) Representative pictomicrographs of H\&E staining and OMP staining of the olfactory epithelium. Scale bars indicate $50 \mu \mathrm{m}$. B) Quantification of OMP-positive cells per high power field from OMP staining. C) Latency to finding a hidden potato chip. ${ }^{*} p<0.05,{ }^{* *} p<0.01$, *** $p<0.001$ compared with CONT group.
A
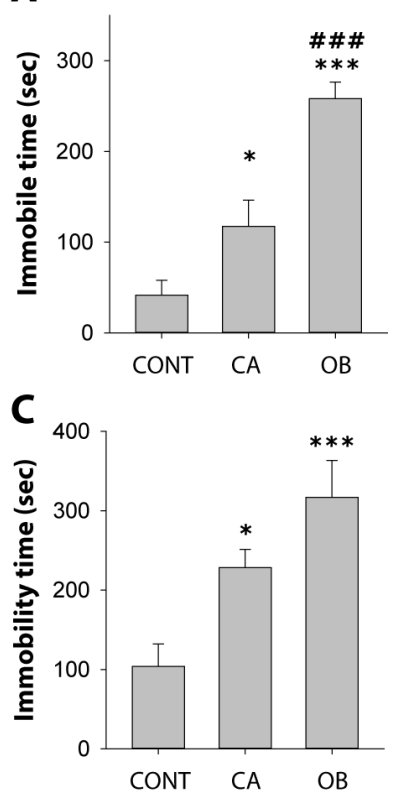

E

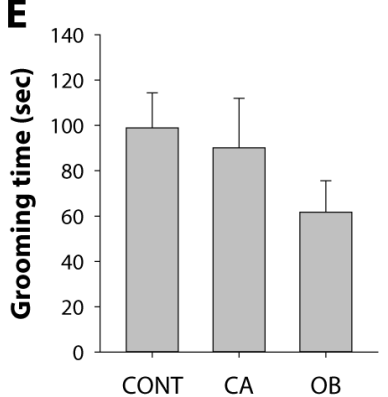

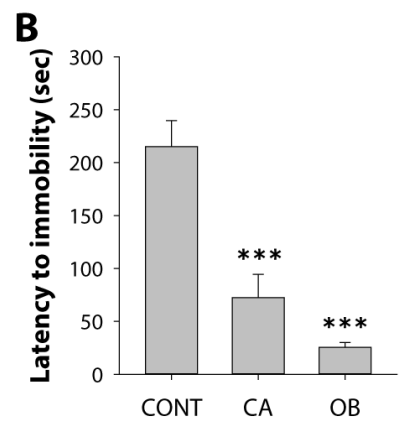

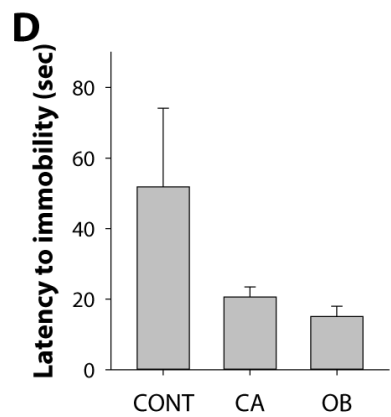

Figure 2. Depressive behavior was observed in CA and OB mice. Behavioral tests including tail suspension, forced swim, and splash tests were performed to assess depression. A) Immobile time in tail suspension test. B) Latency to first immobile period in tail suspension test. C) Immobile time in forced swim test. D) Latency to first immobile period in forced swim test. E) Grooming time in splash test. ${ }^{*} \mathrm{p}<0.05,{ }^{* *} \mathrm{p}<0.01$, ${ }^{* * *} \mathrm{p}<0.001$ compared with CONT group, \#\#\#p<0.001 compared with CA group.

decrease in latency in $\mathrm{CA}$ and $\mathrm{OB}$ mice but did not reach significance (CONT: $51.83 \pm 22.31 \mathrm{sec}, \mathrm{n}=5$; CA: $20.61 \pm 2.83 \mathrm{sec}, \mathrm{n}=5$; OB: $15.04 \pm 2.91 \mathrm{sec}, \mathrm{n}=5$ ) (Figure 2D). The splash test evaluates disturbances in self-care behavior, which is considered parallel to apathetic behavior observed in depression ${ }^{(15)}$. The total grooming time in the splash test was decreased in OB mice but not at a significant degree (CONT: $98.92 \pm 15.42 \mathrm{sec}, \mathrm{n}=5$; CA: $90.11 \pm 21.84 \mathrm{sec}, \mathrm{n}=5$; OB: $61.71 \pm 13.88 \mathrm{sec}, \mathrm{n}=5$ ) (Figure $2 \mathrm{E}$ ). Behavioral test results consistently show that $\mathrm{CA}$ and $\mathrm{OB}$ mice have depression and also a trend of $\mathrm{OB}$ mice showing more depressive behavior than CA mice.

\section{Anxiety was decreased in CA mice when assessed with open} field and elevated plus maze tests

In order to assess anxiety in subject mice, open field and elevated plus maze tests were performed. In the open field test, total time spent in the corner areas was decreased in CA mice (CONT: $1097.7 \pm 138.0 \mathrm{sec}, \mathrm{n}=5 ; \mathrm{CA}: 689.2 \pm 47.4 \mathrm{sec}, \mathrm{n}=5 ;$ OB: $1193.9 \pm$ $103.9 \mathrm{sec}, \mathrm{n}=5$ ) (Figure 3A). Elevated plus maze results exhibited that CA mice spent more time in the open arms (CONT: $91.44 \pm$ 
A

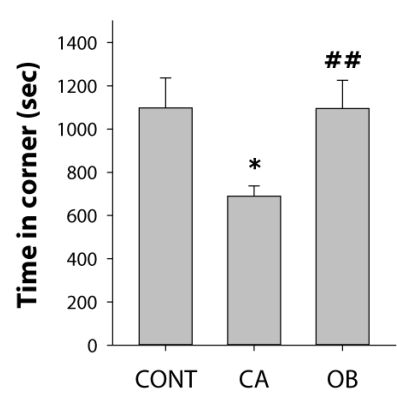

B

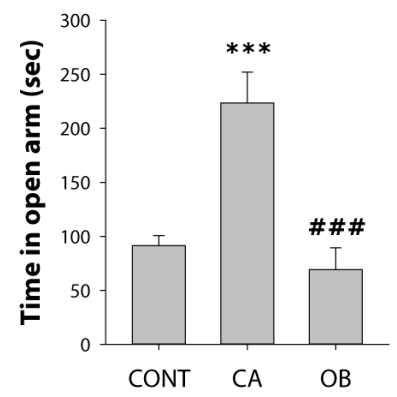

Figure 3. Anxiety was decreased in CA mice. Behavioral tests including open field and elevated plus maze tests were performed to evaluate anxiety. A) Time spent in corner areas in the open field test. B) Time spent in open arms in the elevated plus maze test. ${ }^{*} p<0.05,{ }^{* *} p<0.001$ compared with CONT group, \#\#p<0.01, \#\#\#p<0.001 compared with CA group.

A

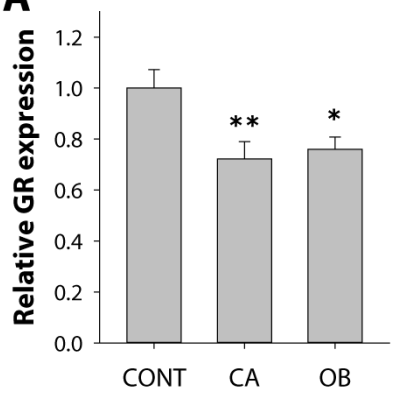

B

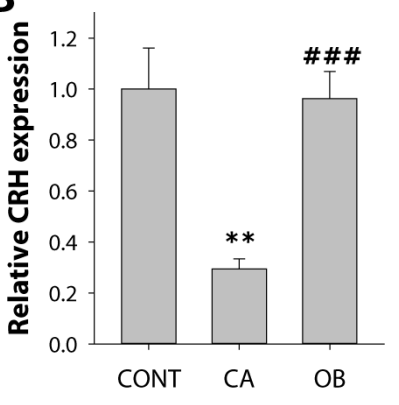

Figure 4. Hypothalamic GR and amygdalar CRH expression was disrupted in CA mice. In order to investigate molecular changes in the brain that correlate with behavioral changes, RNA was extracted from the hypothalamus and amygdala, followed by real-time PCR. A) GR mRNA expression in the hypothalamus. B) CRH mRNA expression in the amygdala. ${ }^{*} \mathrm{p}<0.05,{ }^{* *} \mathrm{p}<0.01$ compared with CONT group, \#\#\# $<0.001$ compared with CA group.

$9.26 \mathrm{sec}, \mathrm{n}=5 ; \mathrm{CA}: 223.36 \pm 28.68 \mathrm{sec}, \mathrm{n}=5 ;$ OB: $69.22 \pm 20.29 \mathrm{sec}$, $\mathrm{n}=5$ ) (Figure 3B). These findings indicate that CA mice, but not OB mice show decreased anxiety.

\section{Hypothalamic GR and amygdalar CRH expression is disrup- ted in CA mice}

To investigate the molecular changes related to the mood changes observed in CA mice, GR in the hypothalamus and $\mathrm{CRH}$ in the amygdala were assessed by real-time PCR. Hypothalamic GR expression was significantly reduced in both $C A$ and OB mice (CONT: $1.000 \pm 0.073, n=5 ; C A: 0.722 \pm 0.068, n=6$; OB: $0.760 \pm 0.048, \mathrm{n}=6$ ) (Figure $4 \mathrm{~A}$ ). Amygdalar $\mathrm{CRH}$ was significantly reduced in CA but not in OB mice (CONT: $1.000 \pm 0.161, \mathrm{n}=3$; CA: $0.294 \pm 0.040, n=3$; OB: $0.962 \pm 0.107, n=4$ ) (Figure 4B). The changes in hypothalamic GR and amygdalar $\mathrm{CRH}$ correspond to the behavioral changes in the aspect of depression and anxiety respectively.

\section{Discussion}

In the present study, mice treated with repeated intranasal instillation of $\mathrm{ZnSO}_{4}$ were utilized to assess the effects of chronic anosmia on behavioral phenotypes and its underlying mechanisms. The behavioral studies demonstrated that $\mathrm{ZnSO}_{4}$-induced chronic anosmia mice show increased depressive behavior and decreased anxiety compared to the control group (Figure 2, 3). Changes in CRH and GR expression in the amygdala and hypothalamus were examined as possible molecular mechanisms. Tail suspension, forced swim, and splash tests were used in the present study to evaluate depressive behavior. Tail suspension and forced swim tests are behavioral tests that assess the escape behavior in inescapable aversive situation ${ }^{(14,16)}$. After a period of intense motor activity the subjects learn that escape is impos- sible and adopt an immobile position, also known as behavioral despair. The total time of immobility during the test period and the latency to the first immobile period are considered to indicate the degree of depression of the subject. Splash test evaluates the degree of self-care behavior by spraying a viscous sucrose solution on the dorsal coat and measuring the time of grooming behavior ${ }^{(17)}$. The decrease in grooming time is considered parallel to apathetic behavior observed in depressive patients ${ }^{(15)}$. Both CA and OB mice showed depressive behaviors when assessed with tail suspension, forced swim, and splash tests. However, interestingly, CA mice appeared to have less severe depression compared to $\mathrm{OB}$ mice (Figure 2). This is a predictable outcome considering that the $C A$ model is induced by a limited disruption of the olfactory epithelium, while the OB model is achieved by radical removal of the olfactory bulb. OB causes dysfunction of the cortical-hippocampal-amygdalar circuit, direct surgical damage and edema, disruption in the blood supply ${ }^{(18)}$. It is also known that retrograde and anterograde degeneration occurs to various regions that are connected to the olfactory bulb ${ }^{(19)}$. Therefore, the OB model can be considered as a more profound depression model. Notably, disturbances in the monoamine system have long been implicated in depression, and have been shown in previous studies on OB mice ${ }^{(19)}$. It is also known that dysregulation in GR can result in suppression of serotonin receptors ${ }^{(2,21)}$. We speculate that the monoamine system may be disturbed in the brains of both the $O B$ and $C A$ model mice.

Hyperactivity of the hypothalamus-pituitary-adrenal (HPA) axis is considered to be one of the main biochemical changes in major depression (22), and it has been reported that GR down-regulation can cause an increase in glucocorticoid levels, possibly due to impaired GR-mediated negative feedback inhibition in 
the hypothalamus and pituitary gland ${ }^{(23)}$. The $\mathrm{CA}$ and $\mathrm{OB}$ mice showed depressive behavioral changes as well as diminished mRNA levels of GR in the hypothalamus which concur with previous studies.

In the open field paradigm the mice are exposed to a novel open space, which triggers anxiety behavior, specifically, moving to the corner of the arena, triggered by the fact that the subject is separated from its social group, and also by agoraphobia ${ }^{(24,25)}$. The elevated plus maze has arms elevated from the floor in order to evoke fear, and the approach-avoidance conflict is assess by time spent in open and closed arms ${ }^{(25,26)}$. Open field and elevated plus maze tests revealed a reduction in anxietylike behavior in CA mice (Figure 3). Hyperactivity and anxiety is considered a typical behavioral change in OB mice ${ }^{(10)}$, but the results in this study failed to show difference in aspect of anxiety between control mice and OB mice. This may be due to the different timeline of experiments since the results in this study were obtained 12 weeks after surgery, while most of the studies on OB mice are performed 1-2 weeks after bulbectomy.

The amygdala is highly recognized as the key brain region for fear and anxiety, and is known to be activated by olfactory signals ${ }^{(27)}$. Injection of a $\mathrm{CRH}$ agonist in the central nucleus of the amygdala $(\mathrm{CeA})$ resulted in increased anxiety, while mice that received a $\mathrm{CRH}$ antagonist injection showed decreased anxietylike behavior ${ }^{(28,29)}$. Kolber and colleagues reported that knockdown of GR in the CeA impaired conditioned fear behavior, and that intraventricular $\mathrm{CRH}$ delivery rescued the deficits. These lines of studies exhibit the important role of $\mathrm{CRH}$ and $\mathrm{GR}$ in the

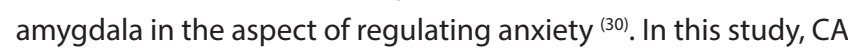
mice showed decreased anxiety in the open field and elevated plus maze tasks, which were accompanied by decreased CRH expression in the amygdala.

Increased depression and coexisting decrease in anxiety-like behavior in CA mice may seem contradictory, considering that anxiety and depression are usually comorbid conditions in human cases ${ }^{(31,32)}$. This uncoupled phenotype of depression and anxiety has been reported in thyrotropin-releasing hormone (TRH) receptor type 2 (TRH-R2) deficient mice ${ }^{(33)}$. The TRH/TRH-R system has been proposed as a major regulatory system within the central nervous system including a role in the modulation of mood, arousal, and circadian rhythm and its functions are thought to be impaired or altered in depression and anxiety (34-38). There are prominent similarities between control of central nervous system function by TRH and $\mathrm{CRH}^{(39)}$. Meanwhile, serotonin $5-\mathrm{HT}_{1 \mathrm{~A}}$ receptor mutant mice and CAMP response element binding protein deficient mice have been reported to show increased anxiety and reduced depression ${ }^{(40,41)}$. These previous studies suggest that the disturbances and/or subtle imbalance in the endogenous neurotransmitters such as monoamines (serotonin and/or norepinephrine) and neurohormones such as $\mathrm{CRH}$ and TRH serve as underlying mechanisms for the unexpec- ted phenotype of increased depression with decreased anxiety observed in CA mice in the current study (Figure 2, 3). Further study is needed to elucidate detailed mechanisms of the mood changes observed in CA mice.

Deterioration in quality of life and increase in prevalence of mood disorders by olfactory loss have been documented in population-based studies ${ }^{(5,6)}$. However, molecular changes in the mood-related brain regions in anosmic mice have not been thoroughly studied. Our results show evidence of the chronic impacts of olfactory loss which was induced in juvenile mice. Since the younger population is more susceptible to changes in olfactory function than the elderly and the brain continues development during childhood and adolescence, olfactory deficits may have higher influence in younger patients ${ }^{(42,43)}$. Direct translation of the current work to human patients may be limited since rodents heavily rely on olfactory cues to detect information of their environment. Nevertheless, data of the present study demonstrates the magnitude of the effects of olfactory loss on the brain and also suggests target brain regions and putative molecular pathways for future research on the comorbid mood disorders in patients with olfactory problems.

\section{Conclusion}

Together, our data show that olfactory deficits induced by chemical ablation of the olfactory epithelium result in behavioral changes related to anxiety and depression as well as corresponding decreased mRNA levels of GR in the hypothalamus and $\mathrm{CRH}$ in the amygdala. While the decline in olfactory function is mainly considered as an outcome of neuropsychiatric diseases, the loss in olfactory inputs may influence brain regions which are closely related with odor processing and emotion. Further research in how olfactory deficits affect emotion and its corresponding brain regions may serve as a rationale for closer management of patients with olfactory deficits.

\section{Acknowledgements}

This study was supported by the Basic Science Research Program through the National Research Foundation of Korea (NRF) funded by the Ministry of Science, ICT and Future Planning (NRF-2014R1A1A1005598 and NRF-2001-0021866) and by grant \#0320130360 (2013-0396) from the SNUH Research Fund.

\section{Authorship contribution}

SA: study design, animal work, data collection and analysis, manuscript writing; HWS: study design, animal work, data collection and analysis, manuscript writing; UM: animal work, data collection and analysis; RK: animal work, data collection; SYJ: study design, data collection; HRJ: data analysis, manuscript writing; JSC: manuscript writing; HSK: study design, data analysis, manuscript writing; DWK, primary investigator: study design, animal work, data collection and analysis, manuscript writing 


\section{Conflict of interest}

\section{The authors state that they have no conflict of interest.}

\section{References}

1. Bramerson A, Johansson L, Ek L, et al. Prevalence of olfactory dysfunction: the skovde population-based study. Laryngoscope 2004; 114:733-737.

2. Temmel AF, Quint C, Schickinger-Fischer B et al. Characteristics of olfactory disorders in relation to major causes of olfactory loss. Arch Otolaryngol Head Neck Surg 2002; 128:635-641.

3. Kern RC. Chronic sinusitis and anosmia: pathologic changes in the olfactory mucosa. Laryngoscope 2000; 110:1071-1077.

4. Upadhyay UD, and Holbrook EH. Olfactory loss as a result of toxic exposure. Otolaryngologic Clinics of North America 2004; 37:1185-1207.

5. Jung YG, Lee JS, and Park GC. Does postinfectious olfactory loss affect mood more severely than chronic sinusitis with olfactory loss? Laryngoscope 2014; 124:2456-2460.

6. Katotomichelakis M, Simopoulos E, Zhang $\mathrm{N}$, et al. Olfactory dysfunction and asthma as risk factors for poor quality of life in upper airway diseases. Am J Rhinol Allergy 2013; 27:293-298

7. Raviv JR, and Kern RC. Chronic sinusitis and olfactory dysfunction. Otolaryngol Clin North Am 2004; 37:1143-1157, v-vi.

8. Kim HY, Kim JH, Dhong HJ, et al. Effects of statins on the recovery of olfactory function in a 3-methylindole-induced anosmia mouse model. Am J Rhinol Allergy 2012; 26:e81-84.

9. Gottfried JA. Central mechanisms of odour object perception. Nat Rev Neurosci 2010; 11:628-641.

10. Zueger M, Urani A, Chourbaji S, et al. Olfactory bulbectomy in mice induces alterations in exploratory behavior. Neurosci Lett 2005; 374:142-146.

11. Jarosik J, Legutko B, Unsicker $K$, et al. Antidepressant-mediated reversal of abnormal behavior and neurodegeneration in mice following olfactory bulbectomy. Exp Neurol 2007; 204:20-28.

12. Hendriksen $\mathrm{H}$, Mechiel Korte $\mathrm{S}$, Olivier B, et al. The olfactory bulbectomy model in mice and rat: One story or two tails? Eur J Pharmacol 2014

13. Buiakova OI, Baker H, Scott JW, et al. Olfactory marker protein (OMP) gene deletion causes altered physiological activity of olfactory sensory neurons. Proc Natl Acad Sci U S A 1996; 93:9858-9863.

14. Castagne V, Moser P, Roux S, et al. Rodent models of depression: forced swim and tail suspension behavioral despair tests in rats and mice. Curr Protoc Neurosci 2011; Chapter 8:Unit 8 10A.

15. Willner P. Chronic mild stress (CMS) revisited: consistency and behavioural-neurobiological concordance in the effects of CMS
Neuropsychobiology 2005; 52:90-110.

16. Porsolt RD, Deniel M, and Jalfre M. Forced swimming in rats: hypothermia, immobility and the effects of imipramine. Eur J Pharmacol 1979; 57:431-436.

17. Santarelli L, Saxe M, Gross C, et al. Requirement of hippocampal neurogenesis for the behavioral effects of antidepressants. Science 2003; 301:805-809.

18. Kelly JP, Wrynn AS, and Leonard BE. The olfactory bulbectomized rat as a model of depression: an update. Pharmacol Ther 1997; 74:299-316.

19. Song $C$, and Leonard BE. The olfactory bulbectomised rat as a model of depression. Neurosci Biobehav Rev 2005; 29:627-647.

20. Lopez JF, Chalmers DT, Little KY, et al. A.E. Bennett Research Award. Regulation of serotonin1A, glucocorticoid, and mineralocorticoid receptor in rat and human hippocampus: implications for the neurobiology of depression. Biol Psychiatry 1998; 43:547-573.

21. Vazquez DM, Neal CR, Jr., Patel PD, et al. Regulation of corticoid and serotonin receptor brain system following early life exposure of glucocorticoids: long term implications for the neurobiology of mood. Psychoneuroendocrinology 2012; 37:421437.

22. van Rossum EF, Binder EB, Majer M, et al. Polymorphisms of the glucocorticoid receptor gene and major depression. Biol Psychiatry 2006; 59:681-688.

23. Pariante CM, and Miller AH. Glucocorticoid receptors in major depression: relevance to pathophysiology and treatment. Biol Psychiatry 2001; 49:391-404.

24. Prut $L$, and Belzung $C$. The open field as a paradigm to measure the effects of drugs on anxiety-like behaviors: a review. European Journal of Pharmacology 2003; 463:3-33.

25. Carola V, D'Olimpio F, Brunamonti E, et al. Evaluation of the elevated plus-maze and open-field tests for the assessment of anxiety-related behaviour in inbred mice. Behavioural Brain Research 2002; 134:49-57.

26. Pellow $S$, Chopin P, File SE, et al. Validation of Open - Closed Arm Entries in an Elevated Plus-Maze as a Measure of Anxiety in the Rat. Journal of Neuroscience Methods 1985: 14:149-167.

27. LeDoux J. The amygdala. Curr Biol 2007; 17:R868-874.

28. Heinrichs SC, Pich EM, Miczek KA, et al. Corticotropin-releasing factor antagonist reduces emotionality in socially defeated rats via direct neurotropic action. Brain Res 1992; 581:190-197.

29. Rassnick S, Heinrichs SC, Britton KT, et al. Microinjection of a corticotropin-releasing factor antagonist into the central nucleus of the amygdala reverses anxiogenic-like effects of ethanol withdrawal. Brain Res 1993; 605:25-32.

30. Kolber BJ, Roberts MS, Howell MP, et al. Central amygdala glucocorticoid receptor action promotes fear-associated $\mathrm{CRH}$ activation and conditioning. Proc Natl Acad Sci U S A 2008; 105:12004-12009.

31. Gorman JM. Comorbid depression and anxiety spectrum disorders. Depress Anxiety 1996; 4:160-168.

32. Wittchen HU, Kessler RC, Pfister H, et al. Why do people with anxiety disorders become depressed? A prospective-longitudinal community study. Acta Psychiatr Scand Suppl 2000:14-23.

33. Sun $\mathrm{YH}$, Zupan B, Raaka BM, et al. TRHReceptor-Type-2-Deficient Mice are Euthyroid and Exhibit Increased Depression and Reduced Anxiety Phenotypes. Neuropsychopharmacology 2009; 34:16011608.

34. Gary KA, Sevarino KA, Yarbrough GG, et al. The thyrotropin-releasing hormone (TRH) hypothesis of homeostatic regulation: implications for TRH-based therapeutics. J Pharmacol Exp Ther 2003; 305:410-416.

35. Yarbrough GG, Kamath J, Winokur A, et al. Thyrotropin-releasing hormone (TRH) in the neuroaxis: therapeutic effects reflect physiological functions and molecular actions. Med Hypotheses 2007; 69:1249-1256.

36. Sattin A. The role of TRH and related peptides in the mechanism of action of ECT. J ECT 1999; 15:76-92.

37. Pekary $A E$, Stevens $S A$, and Sattin A. Circadian rhythms of TRH-like peptide levels in rat brain. Brain Res 2006; 1125:67-76.

38. Gutierrez-Mariscal M, de Gortari P, LopezRubalcava C, et al. Analysis of the anxiolytic-like effect of TRH and the response of amygdalar TRHergic neurons in anxiety. Psychoneuroendocrinology 2008; 33:198213.

39. Steckler T, and Holsboer F. Corticotropinreleasing hormone receptor subtypes and emotion. Biol Psychiatry 1999; 46:14801508.

40. Heisler LK, Chu HM, Brennan TJ, et al. Elevated anxiety and antidepressant-like responses in serotonin 5-HT1A receptor mutant mice. Proc Natl Acad Sci U S A 1998; 95:15049-15054

41. Gur TL, Conti AC, Holden J, et al. CAMP response element-binding protein deficiency allows for increased neurogenesis and a rapid onset of antidepressant response. Journal of Neuroscience 2007; 27:78607868.

42. Hummel T, and Nordin S. Olfactory disorders and their consequences for quality of life. Acta Otolaryngol 2005; 125:116-121.

43. Giedd JN, Blumenthal J, Jeffries NO, et al. 
Brain development during childhood and adolescence: a longitudinal MRI study. Nat Neurosci 1999; 2:861-863

\section{Dae Woo Kim \\ Department of Otorhinolaryngology, Head and Neck Surgery, Boramae Me- dical Center, Seoul National University College of Medicine, 425 Shindaebang 2-dong, Dongjak-gu, Seoul 156-707, Republic of Korea}

Tel: $+82-2-870-2446$

Fax: $+82-2-831-2826$

E-mail:kicubi@daum.net
Hye-Sun Kim

Department of Pharmacology and Biomedical Sciences, Seoul National University College of Medicine, 103 Daehak-ro, Jongno-gu, Seoul 110-799, Republic of Korea

Tel: $+82-740-8298$

Fax: $+82-745-7996$

E-mail: hyisun@snu.ac.kr 